\title{
Virally-Induced, Intracellular Biofilms; Novel Findings in Molluscum Contagiosum
}

Herbert B. Allen ${ }^{*}$ Rina M. Allawh and Shefali Ballal

Department of Dermatology, College of Medicine, Drexel University

*Corresponding author: Herbert B. Allen, Department of Dermatology, College of Medicine, Drexel University, 219 N Broad St. 4th Floor Philadelphia, PA 19107, Tel: 215762 5550; Fax: 215762 5570; E-mail: hba25@drexel.edu

Received date: October 10, 2017; Accepted date: October 24, 2017; Published date: October 26, 2017

Copyright: @2017 Allen HB. This is an open-access article distributed under the terms of the Creative Commons Attribution License, which permits unrestricted use, distribution, and reproduction in any medium, provided the original author and source are credited.

\begin{abstract}
Both the presence and impact of biofilms have proved to be ground breaking regarding early diagnosis and treatment in acute and chronic cutaneous, neurological and other internal diseases. Further, biofilms and the activation of the innate immune system have added clarity to the pathogenesis of those diseases. Our current observations are the first to demonstrate viral biofilms in skin disease; these observations are also the first to demonstrate intracellular biofilms in skin disease. We have observed these in lesions of Molluscum contagiosum (MC). The only previous observation of viral-induced biofilms has been with the HTLV-1 virus. The essential elements of a biofilm are extracellular polysaccharides (EPS) that form the bulk of the biomass, and amyloid fibers that form the proteinaceous infrastructure of the biofilm. Histopathology of skin lesions revealed positive periodic acid Schiff (PAS) and positive Congo red (CR) and crystal violet (CV) stains within MC lesions. The PAS stains the EPS while the Congo red and crystal violet stain the amyloid. Similar staining was absent both in controls and in surrounding skin; this is strong support for the hypothesis that the virus "hi-jacks" the cell's DNA and makes "intra"cellular biofilms.
\end{abstract}

Keywords: Viral biofilms; Intracellular; Molluscum contagiosum; Dermatopathology

\section{Introduction}

We present, for the very first time, observations that a virus, Molluscum contagiosum (MC), makes biofilms in a skin disease. Only once in the medical literature has a virus been shown to make biofilms, namely the HTLV-1 virus [1]. Further, we present the novel finding that the MC virus causes biofilms to be made inside epidermal cells which is the first instance of "intra"cellular biofilms in dermatologic disease. We have shown this with histopathology of MC and have identified the principal elements of a biofilm (polysaccharides and amyloid) in molluscum lesions by utilizing periodic acid Schiff (PAS) and Congo red (CR) stains [2]. The amyloid was further confirmed with crystal violet $(\mathrm{CV})$ staining. The MC lesions from ten patients were studied.

\section{Methods}

This study was approved by the Drexel University College of Medicine Institutional Review Board.

Ten histologic specimens of MC were examined microscopically by four dematopathologists. Hematoxylin and eosin $(\mathrm{H}+\mathrm{E}), \mathrm{PAS}, \mathrm{CR}$ and $\mathrm{CV}$ staining was performed. Ten control specimens from cutaneous lesions of atopic dermatitis were examined with the same staining procedures. Each of the stained specimens was examined by four dermatopathologists.

\section{Results}

The diagnosis of $\mathrm{MC}$ on routine $\mathrm{H}+\mathrm{E}$ staining was readily apparent with each specimen demonstrating the hallmark features of a molluscum lesion: central punctum, lesional epidermal hyperplasia, and typical Henderson-Patterson bodies. The PAS stains revealed focal intracytoplasmic staining in the Malpighian cells just above the basal zone. (Figure 1) The CR stains were positive in a similar location, as were the CV stains. (Figure 2) The atopic dermatitis specimens showed no similar intracytoplasmic staining in the Malpighian cells; they did show staining in the distal sweat ducts (which is the pathologic signature in atopic dermatitis) [2]. The positive staining was present in $10 / 10$ specimens $\left(P=0.001, \chi^{2}\right)$. Each specimen also served as its own control with the lesions showing changes and the adjacent (normal) epidermis demonstrating no similar findings.

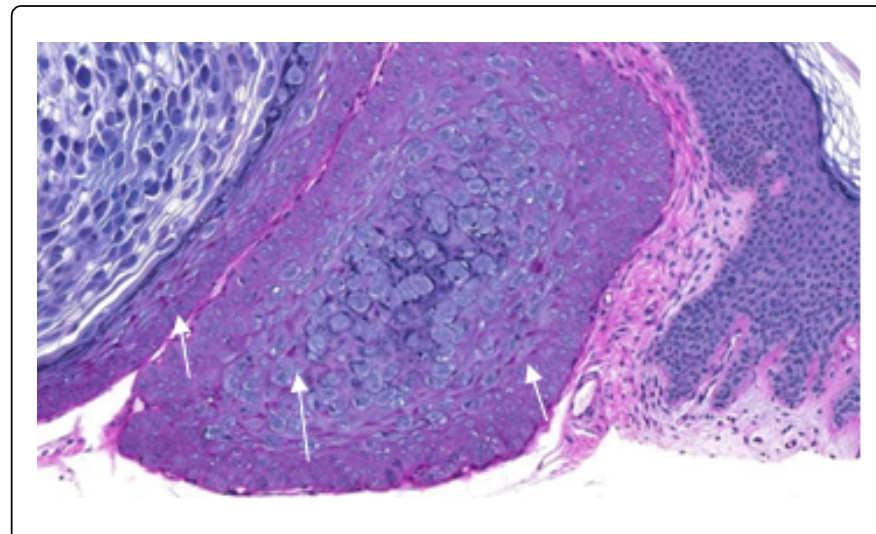

Figure1: PAS positive deposits in the Malpighian cells above the basal layer (arrows). This represents staining of the polysaccharides in a biofilm. Similar deposits are not found in the adjacent epidermis. Molluscum bodies are clearly present (PAS stain 10X). 


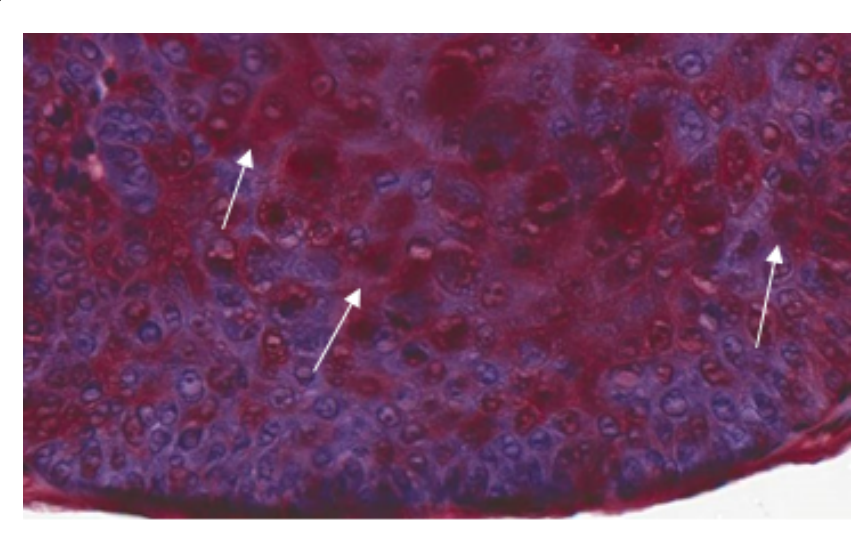

Figure 2: Congo red deposits noted in the Malpighian cells (arrows). This represents staining of the amyloid in biofilms (Congo red stain 40X).

\section{Discusssion}

The PAS, CR, and CV histopathologic stains were positive in the lesions of MC (and negative in the controls and surrounding skin); this is evidence that the virus is creating an "intra"cellular biofilm inside lesional epidermal cells. More correctly, the virus is inducing the epidermal cells to create a biofilm that envelops the virus particles. A biofilm is typically composed of microbes, "extra"cellular polysaccharides, amyloid, DNA, fatty acids, protein, dead cells, exporter cells, and water channels [3]. The PAS stains the polysaccharides in the biofilm, and the CR and CV stain the amyloid that forms the infrastructure of the biofilm. This is similar to those biofilms that we have demonstrated in atopic dermatitis, psoriasis, tinea versicolor and tertiary Lyme disease [2,4-6]. The PAS, CR, and $\mathrm{CV}$ stain the essential components of the biofilms associated with those lesions.

If the same parameters are present with viruses as with other organisms where ten microbes (in any direction) are necessary to make a "quorum" and begin forming a biofilm [7] the smallest size for a MC biofilm would be $0.003 \mu$ given the size of the MC organisms as $1 \times 2 \times$ $3 \mathrm{~nm}$. This calculation would lead to a total volume for that biofilm of $0.014 \mu$, and that volume would contain approximately 2400 viral organisms. This size biofilm would fit handily inside a keratinocyte. For comparison, because of the larger size of the spirochetes (Lyme and dental), the smallest spirochetal biofilm in Alzheimer's disease contains 250 organisms [7]. Whether the same parameters exist in intracellular $v s$ extracellular biofilms regarding the size needed for a quorum of microbes necessary to form biofilms is not fully understood.

The only viral biofilm noted to date is that produced by HTLV-1. That biofilm is present at the borders of the "infected" lymphocytes. The HTLV-1 "hijacks" cell proteins to create the extracellular biofilm [1]. The location of the MC biofilm, on the other hand, is clearly intracytoplasmic; the concept of "intra"cellular biofilms is well established and has been seen in such diverse conditions as urinary tract disease, pneumonitis and Alzheimer's disease [8]. The intracellular microbes in a biofilm are doubly protected from the immune system and other disease modifying agents. Viruses have been shown to assist bacteria (filamentous phages and Pseudomonas) in biofilm production and to enhance biofilm growth (Pseudomonas and respiratory syncytial virus) via dysregulation of immunity from alteration of iron metabolism $[9,10]$. This may be a potential role for the Herpes simplex virus that has been found in the brains of Alzheimer's patients [11] namely assisting the spirochetes that are present there to create biofilms and activate the innate immune system [3].

Treatment that might arise from this observation could possibly involve a biofilm dispersing agent [12] but whether that agent would penetrate through the punctum to the depths of the lesion and then through the cell wall, is questionable. This work does offer a protocol to investigate other viral diseases to discover whether those create biofilms. This is compelling in that most organisms prefer to live in communities rather than in the planktonic state [13].

\section{References}

1. Pais-Correia AM, Sachse M, Guadagnini S, Robbiati V, Lasserre R (2010) Biofilm-like extracellular viral assemblies mediate HTLV-1 cell-to-cell transmission at virological synapses. Nat Med 16: 83-90.

2. Allen HB, Vaze ND, Choi C, Hailu T, Tulbert BH, et al. (2014) The presence and impact of biofilm-producing staphylococci in atopic dermatitis. JAMA Dermatol 150: 260-265.

3. Allen HB, DiBiagio JR, Joshi SG (2016) The pathway to Alzheimer's disease from spirochetes to amyloid- $\beta$. J Alzheimer's Dis.

4. Zhang J, Shaver C, Neidig L, Jones K, Cusack CA, et al. (2017) Toll-like receptor 2 and its relationship with streptococcus in psoriasis. SKIN med 15: 27-30.

5. Allen HB, Goyal K, Ogrich L, Joshi S (2015) Biofilm formation by Malassezia furfur/ovale as a possible mechanism of pathogenesis in tinea versicolor. J Clin Exp Dermatol Res 6: 311.

6. Allen HB, Vin H, Warner C, Joshi S (2016) Lyme disease: beyond erythema migrans. J Clin Exp Dermatol Res 2016 7: 330.

7. Allen HB (2016) Alzheimer's disease: Assessing the role of spirochetes, biofilms, the immune system, and beta amyloid with regard to potential treatment and prevention. J Alz Dis 53: 1271-1276.

8. Allen HB, Allawh R, Touati A, Katsetos C, Joshi SG (2017) Alzheimer's Disease: The novel finding of intracellular biofilms. J Neuroinfect Dis 8: 247.

9. Racaniello V (2017) Viruses help form biofilms.

10. Hendricks MR, Lashua LP, Fischer DK, Flitter BA1, Eichinger KM (2016) Respiratory syncytial virus infection enhances Pseudomonas aeruginosa biofilm growth through dysregulation of nutritional immunity. Proc Natl Acad Sci USA 113: 1642-1647.

11. Itzhaki RF (2014) Herpes simplex virus type 1 and Alzheimer's disease: increasing evidence for a major role of the virus. Front Aging Neurosci. 6: 202.

12. Allen HB, Kim JY, Warner C, Joshi S (2015) Penicillin: the new/old wonder drug. J Drug MetabToxicol 6: 4.

13. Hernández-Jiménez E, Toledano V, Vallejo-Cremades MT, Muñoz A, Largo C, et al. (2013) Biofilm vs. planktonic bacterial mode of growth: Which do human macrophages prefer? Biochem Biophys Res Comm 441: 947-952. 